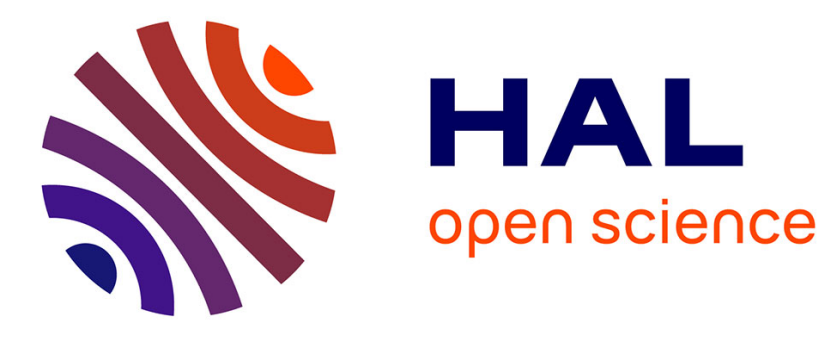

\title{
Sand infiltration into a gravel bed: a mathematical model
}

\author{
A. Herrero, Céline Berni
}

\section{To cite this version:}

A. Herrero, Céline Berni. Sand infiltration into a gravel bed: a mathematical model. Water Resources Research, 2016, 52, 14 p. 10.1002/2016WR019394 . hal-01617133

\section{HAL Id: hal-01617133 \\ https://hal.science/hal-01617133}

Submitted on 16 May 2020

HAL is a multi-disciplinary open access archive for the deposit and dissemination of scientific research documents, whether they are published or not. The documents may come from teaching and research institutions in France or abroad, or from public or private research centers.
L'archive ouverte pluridisciplinaire HAL, est destinée au dépôt et à la diffusion de documents scientifiques de niveau recherche, publiés ou non, émanant des établissements d'enseignement et de recherche français ou étrangers, des laboratoires publics ou privés. 


\section{Water Resources Research}

\section{RESEARCH ARTICLE Sand infiltration into a gravel bed: A mathematical model}

\subsection{2/2016WR019394}

Key Points:

- A mathematical model is proposed to reproduce fine sediment infiltration

into a river bed

- The occurrence of bridging or unimpeded static percolation is properly reproduced

- Differences between calculated and measured sand content may be due to subsurface water flow

Correspondence to:

A. Herrero,

aherrero@icra.cat

Citation:

Herrero, A., and C. Berni (2016), Sand infiltration into a gravel bed:

A mathematical model, Water Resour. Res., 52, doi:10.1002/2016WR019394.

Received 22 JUN 2016 Accepted 31 OCT 2016 Accepted article online 7 NOV 2016

(C) 2016. American Geophysical Union All Rights Reserved.

\author{
A. Herrero ${ }^{1,2}$ and C. Berni ${ }^{2}$ \\ ${ }^{1}$ Catalan Institute for Water Research, Girona, Spain, ${ }^{2}$ Irstea, UR HHLY, Hydrology-Hydraulics, Villeurbanne, France
}

\begin{abstract}
Fine sediment infiltration into a river bed is a physical process affected by different human actions and has several environmental, socioeconomic, and river morphology consequences. A theoretical model is proposed herein aiming to reproduce the fine sediment content depth profile resulting from the infiltration of fine sediment into an initially clean gravel bed. The model is based on the probability of infiltrating particles to be trapped in a pore throat formed by three bed particles. The model is tested against previous experimental results and is found to reproduce adequately the occurrence of the two infiltration mechanisms reported by previous studies: bridging and unimpeded static percolation.

Theoretical depth profiles are found to underestimate fine sediment content at the bed subsurface (below 2-3 gravel diameter depth) compared to the laboratory results. This may be due to hyporheic flow that is not taken into account in our model. In flow experiments, the particles previously infiltrated and deposited might be destabilized by pore water flow and their fall down to the bed might be magnified.
\end{abstract}

\section{Introduction}

Fine sediment (FS) infiltration into a river bed formed by coarser material occurs frequently in mountain and piedmont streams. This process modifies significantly the structure and the physical properties of the bed as well as the hyporheic exchange at the sediment-water interface. The access of nutrients and oxygen to the subsurface is affected. It impacts the river ecosystem: fish spawning [Greig et al., 2007], macrophytes root length [Wood and Armitage, 1997], or the habitat of subsurface invertebrates [Jones et al., 2012]. Moreover, most of the contaminant substances in a river are attached to suspended fine sediment [Walling et al., 2003]. It is thus crucial to determine where they will finally settle. Current management of rivers often leads to fine sediment fluxes that are significantly modified by human activities [Morris and Fan, 1998]. In particular, water and sediment releases from dams generate fine sediment pulses that can potentially infiltrate into the river bed downstream [Cui and Wilcox, 2005; East et al., 2015]. Understanding the physics of FS infiltration can help to perform optimal dam operations that minimize the harmful environmental consequences mentioned above. FS infiltration also reduces bed permeability and affects the efficiency of infiltration wells that take water from aquifers connected to the river [Wooster et al., 2008; Blaschke et al., 2003]. Lastly, considering and quantifying FS infiltration can help to improve morphological models that evaluate river evolution. First, infiltrated sediment does not directly affect the bed topography [Frings et al., 2008]. Second, the incipient motion of the coarse sediment that forms the bed substrate changes when the bed is clogged [Wilcock et al., 2001; Wilcock and Crowe, 2003]. Finally, the presence of fine sediment changes bed roughness, both by modifying the bed surface structure and by altering water exchange at the sediment-water interface [Manes et al., 2011; Blois et al., 2012].

FS infiltration has been the main focus of different laboratory analyses [Einstein, 1968; Schälchli, 1992; Wooster et al., 2008; Gibson et al., 2009, 2010, 2011] and field works [Lisle, 1989; Evans and Wilcox, 2013]. Their observations highlight the occurrence of two different infiltration mechanisms: (i) the formation of a surface clogged layer due to the trapping of fine particles at the pore throats (bridging process) and (ii) the infiltration of fine sediment down to an eventual impermeable layer and subsequent filling of the bed pores over the whole depth (unimpeded static percolation, USP) [Kleinhans, 2002]. The occurrence of one mechanism or the other depends mainly on the size ratio between the bed substrate and the infiltrating sediment [Gibson et al., 2010] and on the standard deviation of both grain size distributions [Huston and Fox, 2015].

Some studies cope with this issue from a mathematical point of view [Lauck, 1991; Cui et al., 2008]. They are mainly based on the introduction of a trapping coefficient that describes the probability of fine sediment to 


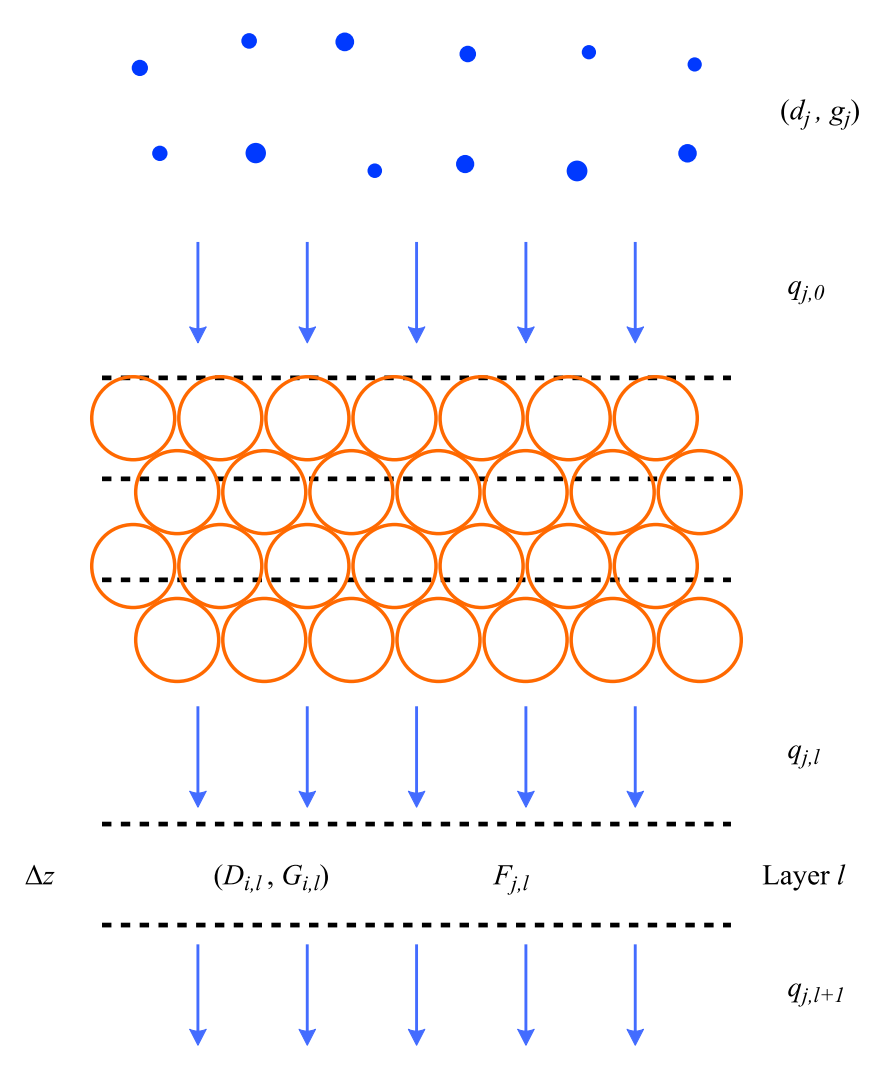

Figure 1. Scheme of the infiltration process. be trapped when travelling a vertical unit distance into the bed. If we assume that this trapping coefficient is constant (temporally and spatially), FS content should decay exponentially down in the bed. Wooster et al. [2008] found this hypothesis to be consistent with their laboratory observations, and proposed a semiempirical equation to compute the trapping coefficient as a function of the characteristic size and the standard deviation of the coarse and fine sediment. Leonardson [2010] analyzed the FS content depth profiles obtained by Gibson et al. [2009, 2010] and found that taking into account that the trapping coefficient changes with the FS content improves their representation.

Based on the ideas of Lauck [1991], this work proposes a mathematical model to reproduce the fine sediment infiltration process and calculate the FS content depth profile of a clogged bed at equilibrium. The development of the mathematical model is carried out first. Then, the model is tested against previous laboratory experimental results

[Gibson et al., 2009, 2010]. The different hypotheses and the performance of the model are discussed next and some final conclusions are drawn.

\section{Development of the Mathematical Model}

The mathematical model that is developed here aims at quantifying the FS content within a gravel bed which can be infiltrated when sand-sized sediment-laden flow it is transported above the surface. We consider an immobile gravel bed of finite depth $h_{b}$. The bed is vertically discretized into several horizontal layers. Grain size distributions (GSD) of both gravel $\left(D_{i}, G_{i}\right)$ and sand $\left(d_{j}, g_{j}\right)$ are known. $D_{i}$ and $d_{j}$ are the diameters resulting from the discretization of the GSD after the sieving process for gravel and sand, respectively, and $G_{i}$ and $g_{j}$ are the weight fraction finer than the corresponding diameter for gravel and sand, respectively. Sand is transported over the bed surface and infiltrates down to the bed at a rate equal to $q_{T o t, 0}$. This infiltration rate is divided into the mass fluxes corresponding to each sand size fraction, $q_{j, 0}$, based on sand GSD $\left(g_{j}\right)$. One specific layer (layer $l$ ) is first considered. Sand-sized sediment enters this layer across the upper boundary (Figure 1). The mass flux of sand that enters is $q_{l}$ (sand volume per bed surface unit and time unit), which is subdivided into $q_{j, l}$, the mass flux associated with each diameter $d_{j}$. As sand grains infiltrate into the layer they get trapped in the pore throats that are too small to let them pass. This fact modifies the GSD of the bed layer $\left(D_{i}, G_{i}\right)$, with $i$ varying from 1 to $n$, where $n$ represents the number of classes of both fine and coarse sediment. When advancing down the bed, the mass flux then decreases and $q_{j, l}>q_{j, 1+1}$. Sand keeps infiltrating within the Ith layer until this layer or one above is clogged, which prevents further sand grains from entering it.

Following Lauck [1991], the trapping coefficient $\beta_{j}$ is defined as the probability of an infiltrating fine grain with a certain diameter $d_{j}$ to be trapped in a pore throat formed by three bed grains. This probability is called from here on trapping coefficient and is denoted by $\beta_{j}$.

The distance between two pore throats can be calculated as in Leonardson [2010]: 


$$
\Delta z_{p}=\frac{2 D_{g}}{3(1-\theta)}
$$

where $D_{g}$ and $\theta$ are the geometrical diameter and the porosity of the bed sediment, respectively. The average number of pores found by a fine particle when it goes through a layer of thickness equal to $\Delta z$ is $\Delta z / \Delta z_{p}$. Therefore, the probability for a grain of size $d_{j}$ to go through this layer without being trapped is $\left(1-\beta_{j}\right)^{\Delta z / \Delta z_{p}}$, and the fine sediment mass flux of size $d_{j}$ passing across the lth layer is

$$
q_{j, I+1}=q_{j, l}\left(1-\beta_{j}\right)^{\Delta z / \Delta z_{p}}
$$

Deposited sediment modifies the GSD of the bed layer and therefore changes the trapping coefficient for further infiltration. Similarly, fine sediment deposition modifies the layer porosity which is used in equation (1) and subsequently in the mass balance represented by equation (2).

It is therefore necessary to quantify the trapping coefficient $\beta_{j}$, for fine sediment with a specified diameterd $d_{j}$ going through a bed layer with a GSD characterized by $D_{i}$ and $G_{i}$, combining both coarse and fine sediment distributions.

\subsection{Trapping Coefficient}

The probability of a fine sediment particle of diameter $d_{j}$ to get trapped in a pore throat is assumed to be equal to the probability of a pore throat being smaller than $d_{j}$. In other words, it is equal to the cumulative probability distribution of pore throat size, $P_{p}$, evaluated at $d_{j}$. The diameter, $x$, of a pore throat formed by three spherical bed grains can be obtained using Heron's formula [Lauck, 1991]:

$$
\begin{aligned}
& \sqrt{\left(D_{1}+D_{2}+D_{3}\right) D_{1} D_{2} D_{3}}=\sqrt{\left(D_{1}+D_{2}+x\right) D_{1} D_{2} x}+ \\
& +\sqrt{\left(D_{1}+x+D_{3}\right) D_{1} x D_{3}}+\sqrt{\left(x+D_{2}+D_{3}\right) x D_{2} D_{3}}
\end{aligned}
$$

where $D_{1}, D_{2}$, and $D_{3}$ are the diameters of the three particles forming it (Figure 2). Based on equation (3), the probability density function (PDF) of pore throat size, $p_{p}(x)$, can be obtained from the joint probability distribution of three bed particles to form a pore, $p_{3}\left(D_{1}, D_{2}, D_{3}\right)$. This, in turn, depends on the PDF of bed sediment size, $p_{b}(D)$, that describes the probability of choosing a particle with a specific diameter, $D$. It must be noted that the introduction of both equations (1) and (3) implies a simplification of the real geometry. In three-dimensional configurations, fine particle trajectories between pores are not exactly vertical and pores are not necessarily formed by three particles. Nevertheless, we consider that our probabilistic model of FS infiltration can give satisfactory results with this simplified geometry of bed arrangement.

The bed sediment distribution $p_{b}(D)$ is initially unknown and has to be obtained from the GSD, $G_{i}$, which is expressed in terms of weight. Considering a bed sample of one weight unit, both distributions are related as

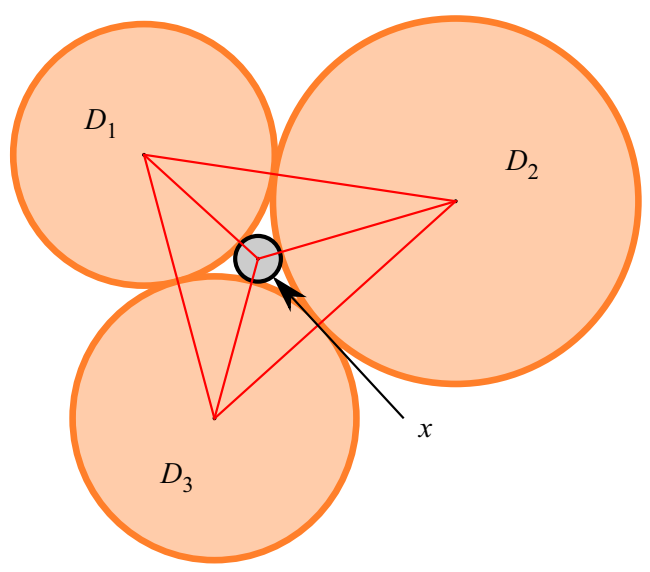

Figure 2. Pore throat size between three bed particles calculated through Heron's formula.

$$
G_{i+1}-G_{i}=\int_{D_{i}}^{D_{i+1}} \gamma D^{3} N p_{b}(D) \mathrm{d} D,
$$

where $\gamma$ is a coefficient such that $\gamma D^{3}$ is the weight of a particle of diameter $D$ (assuming spherical particles, $\gamma=\rho_{g} \pi / 6$, with $\rho_{g}$ the sediment density), and $N$ is the number of bed particles per weight unit, so that $N p_{b}$ $(D) \mathrm{d} D$ is the number of particles per weight unit with a diameter between $D$ and $D+\mathrm{d} D$. As no information is available about the GSD within each interval $\left(D_{i}, D_{i+1}\right), p_{b}(D)$ is assumed to be uniform for each diameter range. The constant value, denoted by $p_{b, i}$, can be obtained as

$$
p_{b, i}=\frac{4}{N \gamma} \frac{G_{i+1}-G_{i}}{D_{i+1}^{4}-D_{i}^{4}}
$$

The normalization of $p_{b}(D)$ implies that 


$$
\sum_{i=1}^{n-1} p_{b, i}\left(D_{i+1}-D_{i}\right)=1
$$

And $N$ can be obtained as

$$
N=\sum_{i=1}^{n-1} \frac{4}{\gamma} \frac{G_{i+1}-G_{i}}{D_{i+1}^{4}-D_{i}^{4}}\left(D_{i+1}-D_{i}\right) .
$$

Some considerations must be taken into account before obtaining $p_{3}\left(D_{1}, D_{2}, D_{3}\right)$ fromp $p_{b}(D)$. The joint probability distribution, $p_{3}\left(D_{1}, D_{2}, D_{3}\right)$ is meant to be used to calculate the pore throat size PDF. It is defined as the probability of observing a pore formed by three particles of diameters $D_{1}, D_{2}$, and $D_{3}$ between the varieties of pores occurring in the bed. The fact that particles of different sizes are associated with a different number of pores needs to be taken into account when evaluating $p_{3}\left(D_{1}, D_{2}, D_{3}\right)$. It is not possible to calculate $p_{3}$ simply as $p_{b}\left(D_{1}\right) \cdot p_{b}\left(D_{2}\right) \cdot p_{b}\left(D_{3}\right)$ and a bias function of the size of the grains needs to be introduced in the calculation of $p_{3}\left(D_{1}, D_{2}, D_{3}\right)$ :

$$
p_{3}\left(D_{1}, D_{2}, D_{3}\right)=C \cdot p_{b}\left(D_{1}\right)\left(D_{1}\right)^{\alpha} p_{b}\left(D_{2}\right)\left(D_{2}\right)^{\alpha} p_{b}\left(D_{3}\right)\left(D_{3}\right)^{\alpha},
$$

where $C$ is a normalizing constant and $\alpha$ is the bias exponent. Positive (or negative) values of $\alpha$ describe a bed where large particles (or small respectively) participates in more pores.

We could assume that the number of pore throats in which a grain participates is proportional to the number of contacts with other grains, which in turn is proportional to the grain surface [Lauck, 1991]. It corresponds to a bias exponent $\alpha=2$ (Figure 3a) [Lauck, 1991]. However, other aspects could be taken into account, making the choice of this parameter uncertain. It should be noted, for example, that the number of fine particles per unit of vertical length is larger than the number of coarse particles (Figure 3b). Therefore, an infiltrating sand particle finds more fine particles than coarse particles when going through a bed layer with a fixed thickness. The bias exponent should then be reduced to 1 . On the contrary, very fine particles, such as sand when compared to gravel, can be deposited on the top of the coarser grains and remain without being part of the bed sediment matrix (Figure 3c), a fact that should increase the value of $\alpha$. The value of the bias exponent changes whether these or other aspects should be taken into account. Its determination is not straight-forward. This point is discussed further in the section 3.

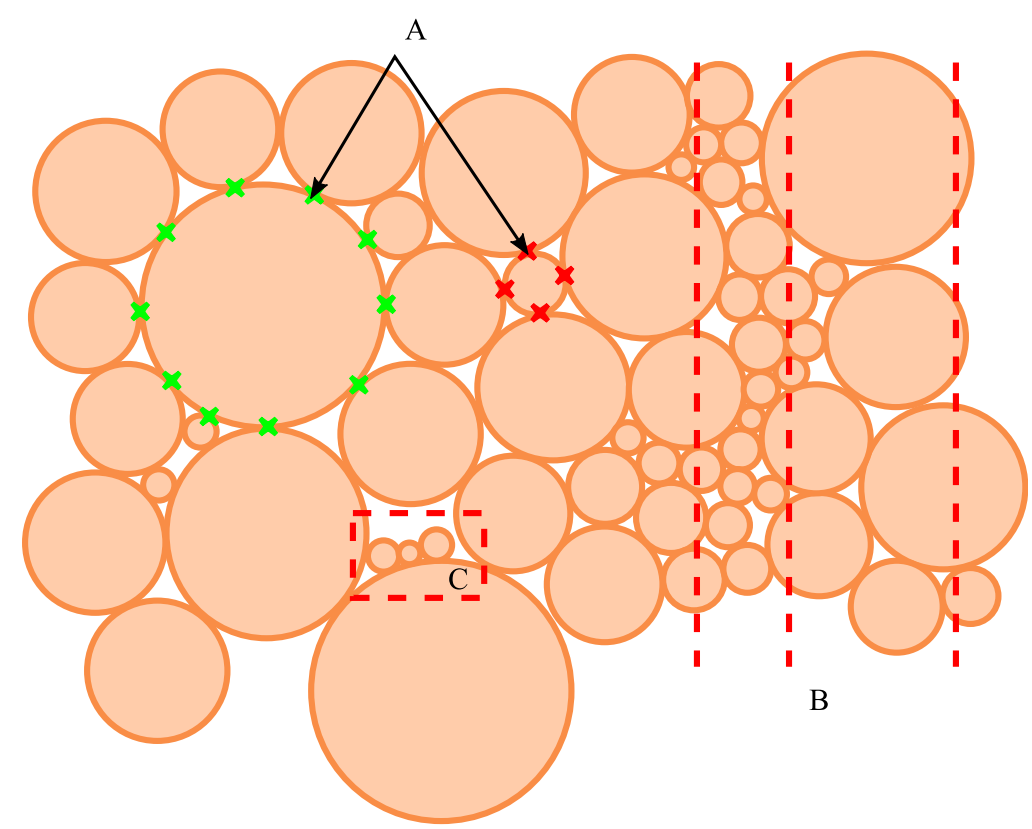

Figure 3. Scheme of sediment patterns that influence the value of the bias parameter, $\alpha$. (a) The number of pores associated with a single grain is proportional to the grain surface; (b) the number of particles per depth unit is inversely proportional to the particle size; (c) some particles do not directly form the bed framework. 
Equation (3) and $p_{3}\left(D_{1}, D_{2}, D_{3}\right)$ can be used to obtain the pore throat size PDF, $p_{p}(x)$. As $x$ cannot be determined explicitly from equation (3), the following procedure is adopted. First, the range of possible bed sediment diameters is discretized and equation (3) is used to compute the pore throat size associated with each combination of three sizes. The smallest pore throat size is that formed by the three smallest bed particles and the largest is the one formed by three coarsest bed particles. The range of pore throat sizes is then discretized in possible values, $x_{k}$, and the pore throat size PDF, $p_{p}(x)$, is assumed to be constant in each interval and denoted by $p_{p, k}$. The value of $p_{p, k}$ is calculated as the sum of the probabilities of all the combinations of particles that form pores with a diameter between $x_{k}$ and $x_{k+1}$ :

$$
p_{p, k}=\sum_{x \in\left(x_{k}, x_{k+1}\right)} p_{3}\left(D_{1}, D_{2}, D_{3}\right)(\Delta D)^{3},
$$

where $\Delta D$ is the interval of discretization of the bed layer GSD.

Based on $p_{p}(x)$, the cumulative distribution of the pore throat size can be calculated as

$$
P_{p}(x)=\int_{0}^{x} p_{p}\left(x^{\prime}\right) d x^{\prime}
$$

Finally, the trapping coefficient $\left(\beta_{j}\right)$ associated with fine sediment of diameter $d_{j}$ is

$$
\beta_{j}=P_{p}\left(d_{j}\right)
$$

\subsection{Time Iteration}

We now consider a gravel channel bed with a specified thickness $\left(h_{b}\right)$ where sand-sized sediment enters through the upper boundary. The evolution of the depth profile of FS content is calculated as follows. The bed is subdivided in horizontal layers with a thickness $(\Delta z)$ equal to the geometrical diameter of the gravel, $D_{g}$. The GSD of the /th layer is characterized by $D_{i, l}$ and $G_{i, l}$. Considering the mass balance in the /th layer, the amount of fine sediment of size $d_{j},\left(\Delta F_{j}\right)_{1}$, accumulated during an interval of time $\Delta t$ is

$$
\left(\Delta F_{j}\right)_{l}=\frac{q_{j, I}-q_{j, I+1}}{\Delta z} \Delta t
$$

The amount of sand trapped in each layer during an interval of time $\Delta t$ is computed using equation (12) in conjunction with equations (1) and (2). Sand deposition changes the GSD of each bed layer. FS content for each class increases by $\Delta F_{j}$, and subsequently changes the bed porosity. Thus, the trapping coefficient $\left(\beta_{j}\right)$ and the mean distance between pore throats $\left(\Delta z_{p}\right)$ appearing in equation (2) need to be recalculated at each time step, considering the updated FS content (and the subsequent change in bed porosity). The new values are used again in equation (2) to obtain sand mass fluxes through each layer which are introduced in equation (12) to calculate the new FS content in each layer.

The deepest layer is considered to be impermeable, hence the trapping coefficient is set to one for all sand sizes. FS content at any layer cannot increase indefinitely but is limited by a specified maximum value that corresponds to a fully clogged layer. This value is calculated as in Leonardson [2010]:

$$
F_{\max }=\theta_{g}\left(1-\theta_{s}\right)\left[1-2.35 \frac{d_{g}}{D_{15}}+1.35\left(\frac{d_{g}}{D_{15}}\right)^{2}\right],
$$

where $F_{\max }$ is the maximum FS content, $\theta_{g}$ is clean gravel porosity, $\theta_{s}$ is sand porosity, $d_{g}$ is sand geometric diameter, and $D_{15}$ is the diameter for which $15 \mathrm{wt} \%$ of the gravel is finer. Once the total FS content in a bed layer reaches this value, this layer is considered to become impermeable for sand and the trapping coefficient is assumed to be one. The iterations stop when the FS content at the surface bed layer reaches $F_{\max }$.

\section{Results}

A numerical code written in MATLAB was developed based on the theoretical model described in the previous section. The input data of the model consist of the GSD of bed (gravel) and infiltrating (sand) sediments, and $q_{T o t, 0}$. The model is initialized with a bed formed by gravel clean of sand. Time step is defined as 


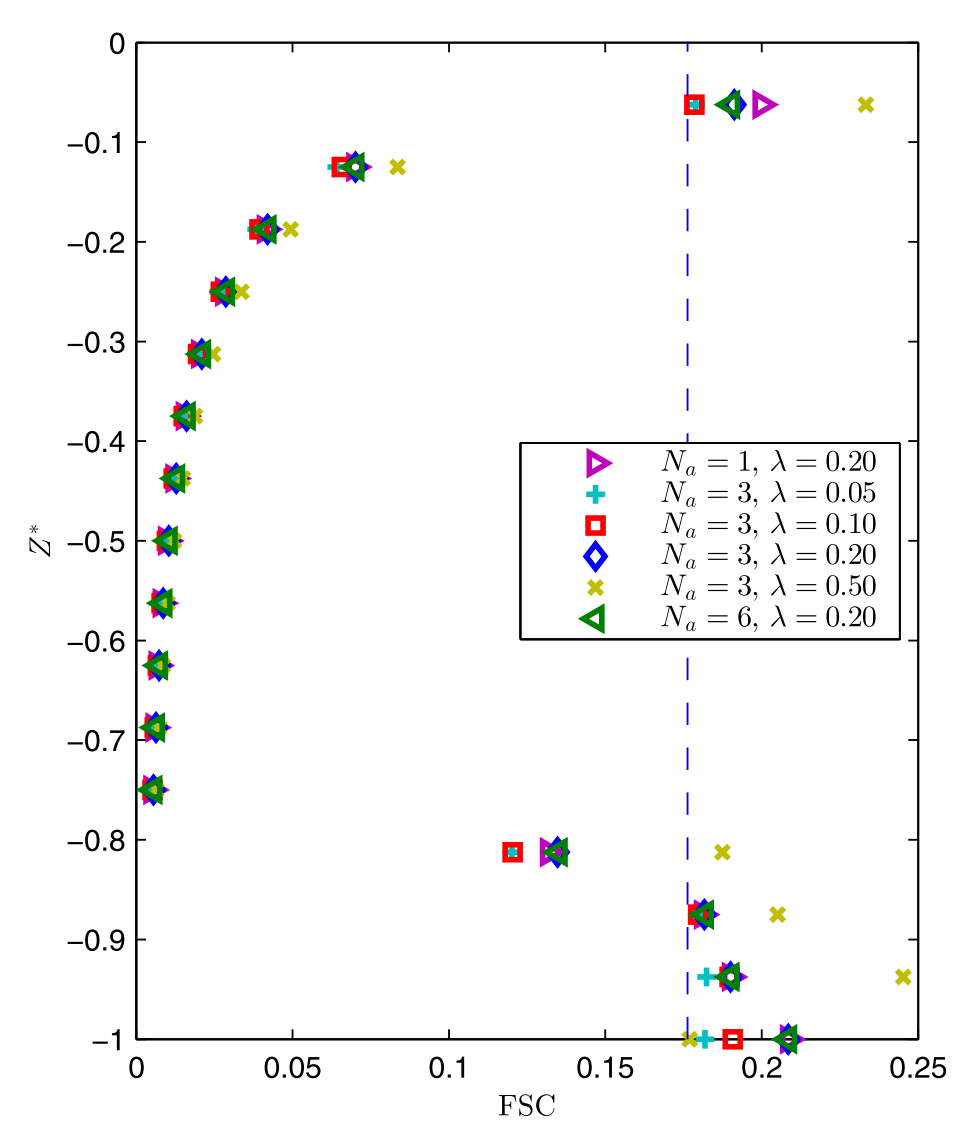

Figure 4. Fine sediment content depth profiles with different discretizations of the grain size distribution $\left(N_{a}\right)$ and the time $(\lambda) . Z^{*}$ is the dimensionless depth, defined as $Z^{*}=z / h_{b}$. Dashed line corresponds to fine sediment content equal to $F_{\text {max }}$.

$$
\Delta t=\lambda \frac{F_{\max } \Delta z}{q_{T o t, 0}},
$$

where $\lambda$ is a parameter that determines the accuracy of time discretization. A base value of 0.2 was adopted for $\lambda$. This means that $\Delta t$ is such that the fine sediment retained in one layer during one time step cannot exceed $20 \%$ of the maximum FS content at that layer. After each time step, the GSD of each layer was updated on the basis of the fine sediment retained. The iterations stop once the surface layer reached the theoretical maximum FS content specified by equation (13).

First, a sensitivity test of the theoretical model was carried out to analyze the influence of the discretizations of the GSD and the time step. We define $N_{a}$ as the number of subdivisions in each interval of the GSD that results from the sieving process. Increasing $N_{a}$ generates a higher number of possible sizes of both infiltrating and bed material. Subsequently, a better representation of pore size PDF is possible and the convolution with infiltrating sediment size PDF provides a better reproduction of the retained fine sediment. The time $\operatorname{step} \Delta t$ is defined in terms of $q_{T o t, 0}$, which implies that the calculated depth profile is not sensitive to $q_{\text {Tot }, 0}$. The results of the model for values of $N_{a}$ between 1 and 6 and values of $\lambda$ between 0.05 and 0.5 are shown in Figure 4. The results do not change significantly within this range. Values of $N_{a}=3$ and $\lambda=0.2$ were considered for all the calculations presented herein, as they implied a reasonable computation time. Total sand flux at the bed surface, $q_{T o t, 0}$, was arbitrarily set to one.

Second, the mathematical model was compared to the experimental results obtained by Gibson et al. [2009]. They measured the FS content depth profile at equilibrium for different GSD of both bed and infiltrating sediment. Their objective was to determine a threshold value for coarse to fine sediment diameter ratio that separates the occurrence of bridging and USP. Three different infiltrating sediments (sand-sized) were infiltrated in the same gravel bed. Their GSDs are detailed in Figure 5. During their experiments, Gibson et al. [2009] performed two analogous tests with each combination of bed and infiltrating sediment; one in open channel flow and one in still water conditions. The open channel flow experiments were performed in a tilting channel with a constant water discharge. Fine sediment was supplied upstream. Still water experiments were carried out in plastic bins where fine sediment was sprinkled over a layer of gravel.

Figure 6 shows the FS content depth profile measured in experiment 1 (IFS1) of Gibson et al. [2009] and computed with the theoretical model considering the same GSDs. Theoretical profiles with different values of the bias parameter, $\alpha$, are shown. The amount of infiltrated sediment at the deep layers increases with $\alpha$. For the highest value $(\alpha=3.5)$ the depth profile is modified significantly and changes from a bridging profile to an approximately uniform profile characteristic of USP. Measurements of Gibson et al. [2009] show higher FS content for infiltration under free flow conditions than during the still water experiments. 


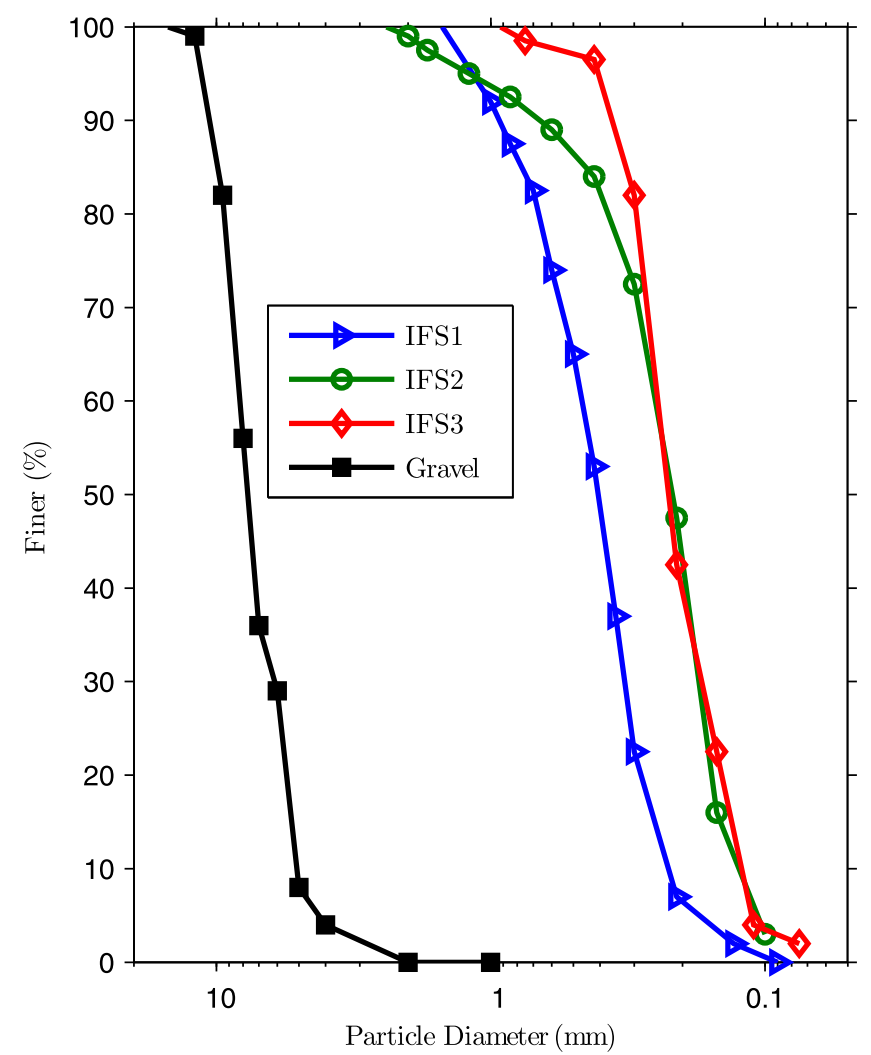

Figure 5. Grain size distributions used in the laboratory experiments performed by Gibson et al. [2009] (IFS: Infiltrated Fine Sediment).
Figure 7 shows the comparison between the modeled and the experimental FS content depth profiles for the different GSDs used by Gibson et al. [2009]. The bias parameter, $\alpha$, was set to 3 for these computations, the value for which a best fit is observed between model and experimental results (see section 4). Experimental results correspond to the still water experiments. Bridging profiles were observed for the types of sand IFS1 and IFS2 and USP for IFS3. Experimental and theoretical results agree well except for the deepest part of the depth profile of experiment IFS2. The FS content computed with the model is close to the maximum FS content, $F_{\text {max }}$. It is a consequence of the impermeable boundary condition imposed in the model. The root-mean-square error is calculated for the three types of fine sediment (IFS1, IFS2, and IFS3) and normalized with the maximum value of FS content for each experimental profile. The obtained values are, respectively, 0.05, 0.29, and 0.16.

Gibson et al. [2010] performed an experimental work involving different types of gravel and infiltrating sediment with 7 and 10 GSDs, respectively ( $D_{50}$ ranging from 2.9 to $9.2 \mathrm{~mm}$ for the gravel and $d_{85}$ ranging from 0.05 to $1.05 \mathrm{~mm}$ for the sand). Following their previous work [Gibson et al., 2009], the objective was to determine more precisely a threshold value that distinguishes bridging and USP profiles of FS content for the different combinations of bed and infiltrating sediment. Coherently with Gibson et al. [2010], equilibrium FS content depth profiles were classified in bridging, transitional and USP profiles. All the theoretical profiles follow a qualitatively similar trend (see for example Model IFS2 in Figure 7). Three parts can be distinguished: (i) a surface layer filled with fine sediment in the surface (FS content equal to $F_{\max }$ ) and with FS content that decreases when going down to the bed (between $Z^{*}=-0.2$ and $Z^{*}=0$ for Model IFS2 in Figure 7); (ii) an intermediate layer with negligible FS content (between $Z^{*}=-0.5$ and $Z^{*}=-0.2$ for Model IFS2 in Figure 7); (iii) a deep clogged layer with FS content $=F_{\max }$, that is a consequence of the impermeable boundary condition (below $Z^{*}=-0.5$ for Model IFS2 in Figure 7). The thickness of this clogged layer at equilibrium depends on the time during which fine sediment is able to infiltrate before FS content at the near-surface layers prevent further fine sediment from infiltrating. Bridging profiles are defined as those where the shallowest layer is filled with $F_{\text {max }}$ and FS content decreases with depth down to the bottom clogged layer. Transitional profiles include FS content depth profiles where the FS content in any of the layers is below $15 \%$ and above $5 \%$ in all of them. USP profiles are defined as those where the clogged layer covers the whole bed and FS content is $F_{\text {max }}$ in all the layers. Figure 8 shows the classification of the different profiles resulting from the experimental work [Gibson et al., 2010] and the theoretical model for a value of $\alpha=3$.

\section{Discussion}

The discussion section is structured as follows: first, the influence and physical meaning of the bias parameter introduced in the model are discussed. Second, the ability of the model to separate bridging and USP profiles is analyzed as well as the suitability of different threshold parameters used in the literature to distinguish between both types of profile. Third, further aspects which are not taken into account by the model and may have an influence on FS content profiles are enumerated and discussed. Last, model 


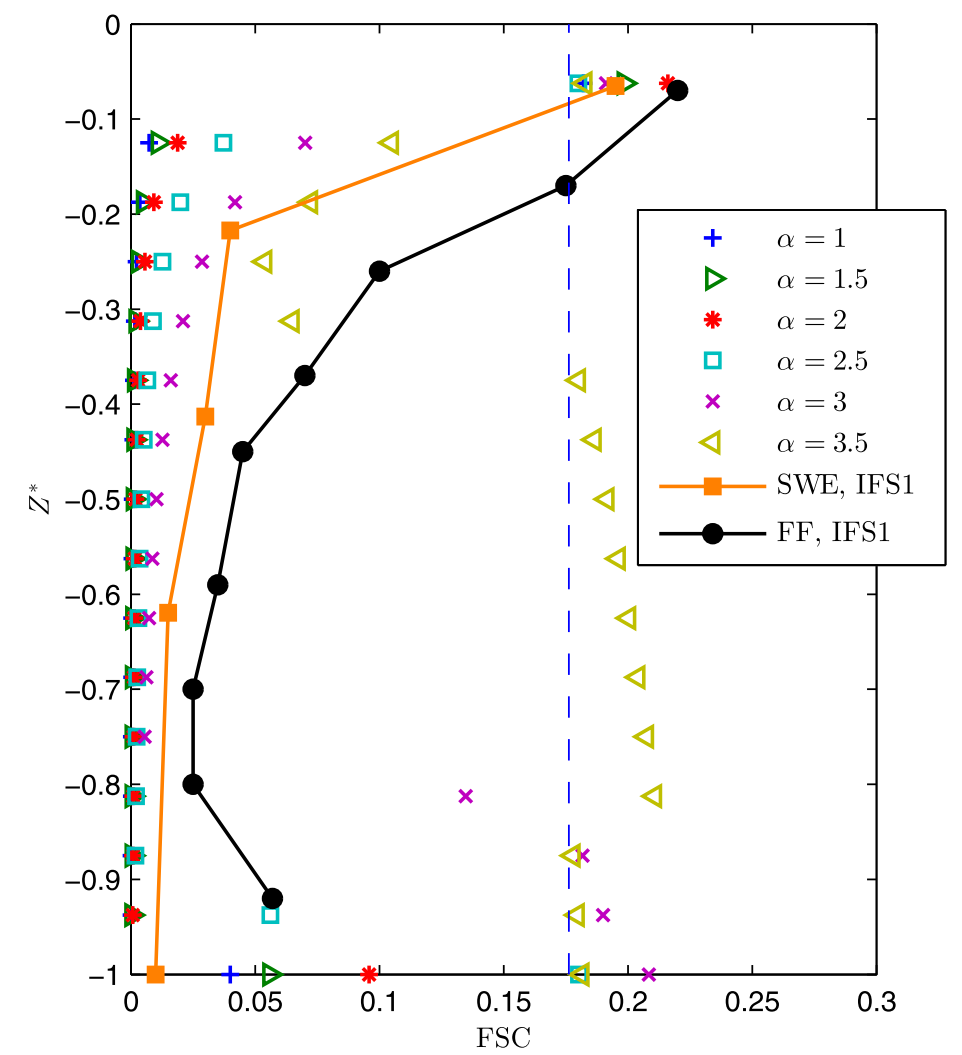

Figure 6. Fine sediment content depth profiles for different values of the bias parameter $\alpha$ compared to experimental results of Gibson et al. [2009] in experiment 1 under free flow conditions (FF IFS1) and in still water conditions (SWE IFS1). Dashed line corresponds to $\mathrm{FSC}=F_{\text {max }}$. Root-mean-square error (RMSE) normalized by the maximum FSC value are $\alpha=1, \mathrm{RMSE}=0.153 ; \alpha=1.5, \mathrm{RMSE}=0.127 ; \alpha=2, \mathrm{RMSE}=0.112 ; \alpha=2.5, \mathrm{RMSE}=0.115$; $\alpha=3, \mathrm{RMSE}=0.049 ; \alpha=3.5, \mathrm{RMSE}=0.606$. results are compared with the ones obtained based on a previous statistical analysis obtained from the literature [Huston and Fox, 2015].

\subsection{Influence of the Bias Parameter}

Figure 6 shows the comparison of the calculated profiles for different values of the bias parameter, $\alpha$. An increase in the bias parameter results in higher FS infiltration down to the deepest layers. This is a consequence of the higher probability of observing coarser particles that form larger pores. The theoretical profile that more accurately reproduces the experimental results is the one corresponding to $\alpha=3$ (root-mean-square error equal to $4.9 \cdot 10^{-2}$, the error is normalized with the maximum experimental FS content). This indicates that the probability for a bed particle to participate in a pore throat is proportional to its volume. A first assumption could be that the number of pore throats in which a bed grain participates is proportional to the number of con-

tact points with adjacent grains. This is proportional to the grain surface and subsequently to the square of its diameter, therefore suggesting a value of $\alpha=2$. A higher value of $\alpha$ could indicate that fine bed grains contribute in fewer pore throats than indicated by their surface. Part of the finest bed grains may not form the bed matrix but they may be deposited in the pores formed by the coarser grains (Figure 3c). This situation could be more likely as the standard deviation of the bed sediment grain size distribution increases.

\subsection{Threshold Between Bridging and USP}

Figure 8 shows to which extent the results of the mathematical model are consistent with the experimental results obtained by Gibson et al. [2010]. A threshold value between 14 and 16 for $D_{15} / d_{85}$ separates the occurrence of bridging and USP for both the experimental data and the model results. It can be noted though that this threshold does not perfectly distinguish both mechanisms. Huston and Fox [2015] suggested another parameter to define this threshold, namely the ratio between geometrical diameters of coarse and fine sediment divided by the variance of the coarse sediment grain size distribution: $D_{\mathrm{g}} /\left(d_{\mathrm{g}} \sigma_{g}\right)$. Both parameters aim to compare the pore size of the gravel bed and the diameter of the fine sediment. $D_{\mathrm{g}} /$ $\sigma_{\mathrm{g}}$ and $D_{15}$ are used as surrogates of the characteristic pore size by Huston and Fox [2015] and Gibson et al. [2010], respectively. In order to discuss the suitability of each threshold parameter, the mathematical model presented herein is first applied to the data of Gibson et al. [2010] to discuss the best way to reproduce the pore size. The choice for the characteristic diameter of the fine sediment will be addressed afterward.

The median pore size of the eight types of gravels used in Gibson et al. [2010] were computed with the model presented herein (equation (10) and $P_{p}(x)=0.5$ ), using $\alpha=3$ and $N_{a}=3$. Results are presented in Figure 9 as a function of $D_{g} / \sigma_{g}$ and $D_{15}$. The coefficients of determination $r^{2}$ of the linear fit through data points are indicated on each panel. Both parameters similarly reproduce the median pore diameter for such grain 


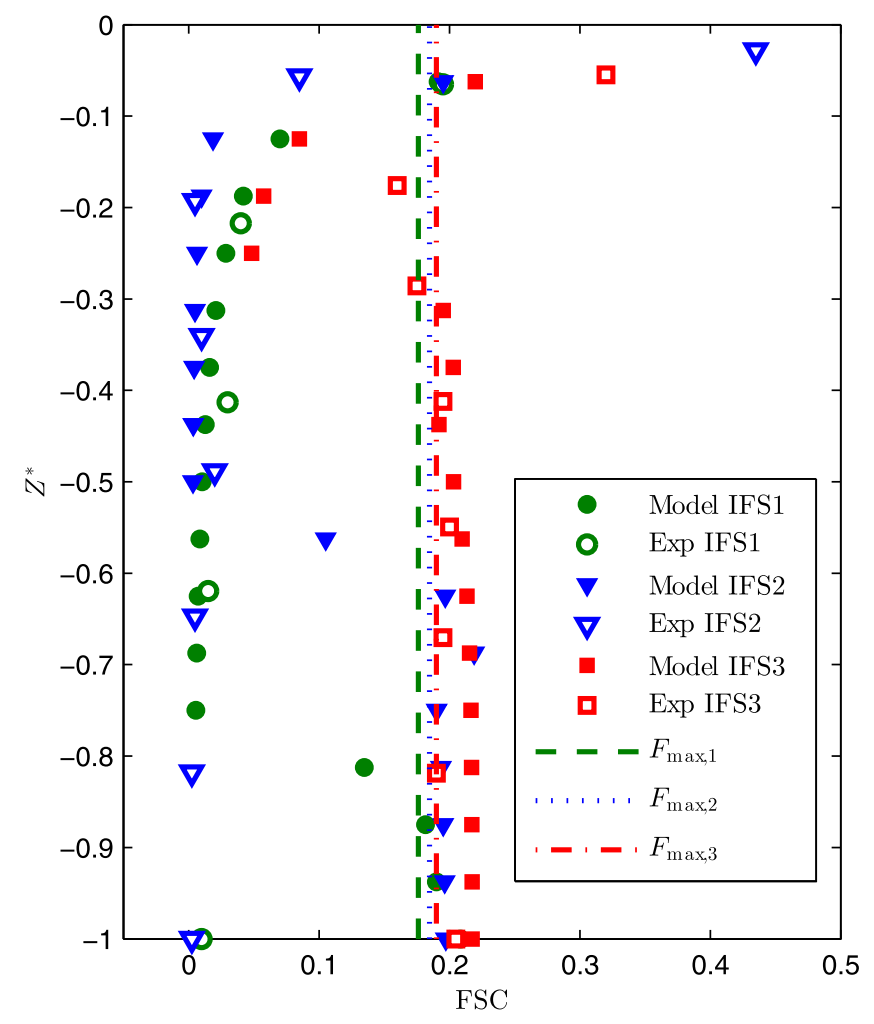

Figure 7. Comparison between the results of the theoretical model with $\alpha=3$ (full symbols) and the experimental results obtained by Gibson et al. [2009] (empty symbols) for three different types of fine sediment (Figure 5). The different dashed lines correspond to the values of $F_{\text {max }}$ of the three different fine sediments. size distributions, and the different slopes of 0.24 and 0.20 for $D_{g} / \sigma_{g}$ and $D_{15}$, respectively, partially explain the different values for the clogging threshold that the authors obtain. It should be noted that natural grain size distributions can display multiple modes and such parameters then fail in reproducing a characteristic pore size diameter.

A characteristic diameter for fine sediment also takes part in the definition of the clogging threshold criteria. Huston and Fox [2015] use the geometric mean diameter while Gibson et al. [2010] consider $d_{85}$. In the model presented herein, each class of fine sediment can be retained independently and this parameter is not critical. The suitability of one or the other option to describe the bridging threshold may be discussed. The threshold proposed by Huston and Fox [2015] $\left(D_{g} /\left(d_{g} \sigma_{g}\right)=27\right)$ can be reinterpreted as a ratio of median pore size to fine geometric diameter of 6.5. This ratio above one could be an indication that several particles smaller than the pore throat arrive simultaneously and form a bridge that is retained in the pore. Multiparticle bridging has been indeed proposed as a mechanism responsible of surface clogging [Huston and Fox, 2015; Valdes and Santamarina, 2006]. Nevertheless, a ratio of 6.5 is too high to be explained by multiparticle bridging. Multiparticle bridging indeed is not stable for pore spaces that are 3-4 times the fine particle diameter [Valdes and Santamarina, 2008]. On the other hand, reinterpreting the threshold value of Gibson et al. [2010] leads to a ratio between pore size and fine sediment size of 2.7. The difference in these threshold values is quite consistent with the difference between $d_{85}$ and $d_{g}$ for the fine sediments used in Gibson et al. [2010] (1.96 average). A possible interpretation of these results is that a pore is blocked by a bridge formed by fine particles belonging to the coarsest fraction of the infiltrating sediment (i.e., two to three particles of size $d_{85}$ and not six to seven of size $d_{g}$ ). This idea supports the proposition of Gibson et al. [2010] to choose $d_{85}$ to characterize infiltrating sediment in the clogging threshold parameter. The size of the coarser infiltrating sediments is determinant for the establishment of a clogged surface layer. We therefore consider the threshold parameter proposed by Huston and Fox [2015] as less suitable than the one proposed by Gibson et al. [2010]. The influence of multiparticle bridging may be a function of the rate at which fine sediment is infiltrated into the bed. This rate would likely affect the probability of two or more particles arriving simultaneously at a pore throat. This discussion underlines a limitation of the model proposed herein that relies on the fact that fine particles arrive to a specific pore throat one by one so that multiparticle bridging is not taken into account. Some other limitations of the model are discussed below.

\subsection{Other Relevant Processes}

In this section, several aspects are discussed which may influence infiltration and are not considered within the model. First, the pore size calculated with Heron's formula (equation (3)) is based on the hypothesis that the pore is formed by three bed grains. However, real bed pore throats may often be formed by four or even more adjacent grains. In this case, pore throat size is larger than in the case of a pore formed by three grains. This can be easily illustrated considering the pore throats formed by three or four identical particles of diameter $D$ (Figure 10). The size of the four-grain pore throat is 2.5 times larger than the three-grain pore 

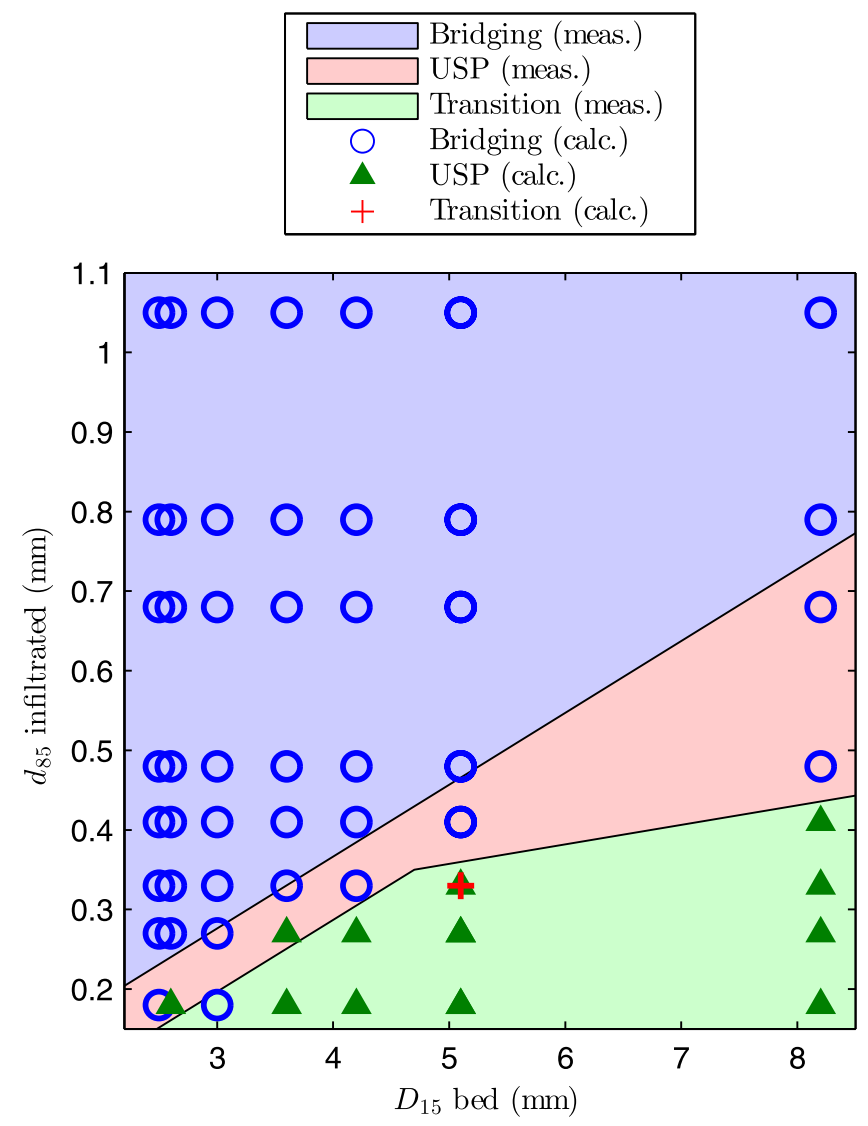

Figure 8. Comparison of bridging and unimpeded static percolation threshold calculated using the theoretical model and the experimental results observed by Gibson et al. [2010]. Symbols are the results of the model presented herein with a bias parameter $\alpha$ equal to 3, whereas the shades in background summarize the results of Gibson et al. [2010]. process, fine particles are transported faster and can infiltrate before coarser particles clog the surface grains and stop the infiltration process. During the still water experiment, coarse and fine particles reach the bed surface almost simultaneously and less sediment is able to infiltrate into the bed before the surface becomes clogged.

Pore scale processes can also explain differences between the model results and the experimental observations. The mathematical model proposed herein considers the blockage of infiltrated grains only at the pore throats. However, fine grains can also be deposited on the top of bed gravel grains. We performed a series of laboratory analysis on silt and sand infiltration (results not published yet) where this process was observed. During the first stage of the tests, silt and sand piles were observed on the top of the bed grains. This process is not considered in this model and may explain the higher fine sediment content observed in the laboratory.

Interstitial flow can also favor higher fine sediment content. Huston and Fox [2015] suggest the influence of pore water velocity on the dispersion of fine particles toward deep layers. Shear stress associated with pore water velocity may be high enough to destabilize some of the deposits that clog the surface layer, causing small landslides that transport fine sediment downward. Some destabilization may occur as a consequence of velocity fluctuations associated with turbulent sweeps. This phenomenon is related to the momentum exchange across the bed surface affecting the effective bed roughness [Manes et al., 2011]. This pattern has been observed by the authors in the laboratory (results not published yet). These aspects may explain the difference between the theoretical and the experimental results. The mathematical model proposed herein is based on a geometrical approach that reproduces well the still water experiments but do not take into account the influence of the flow. The better correspondence of theoretical results with still water 

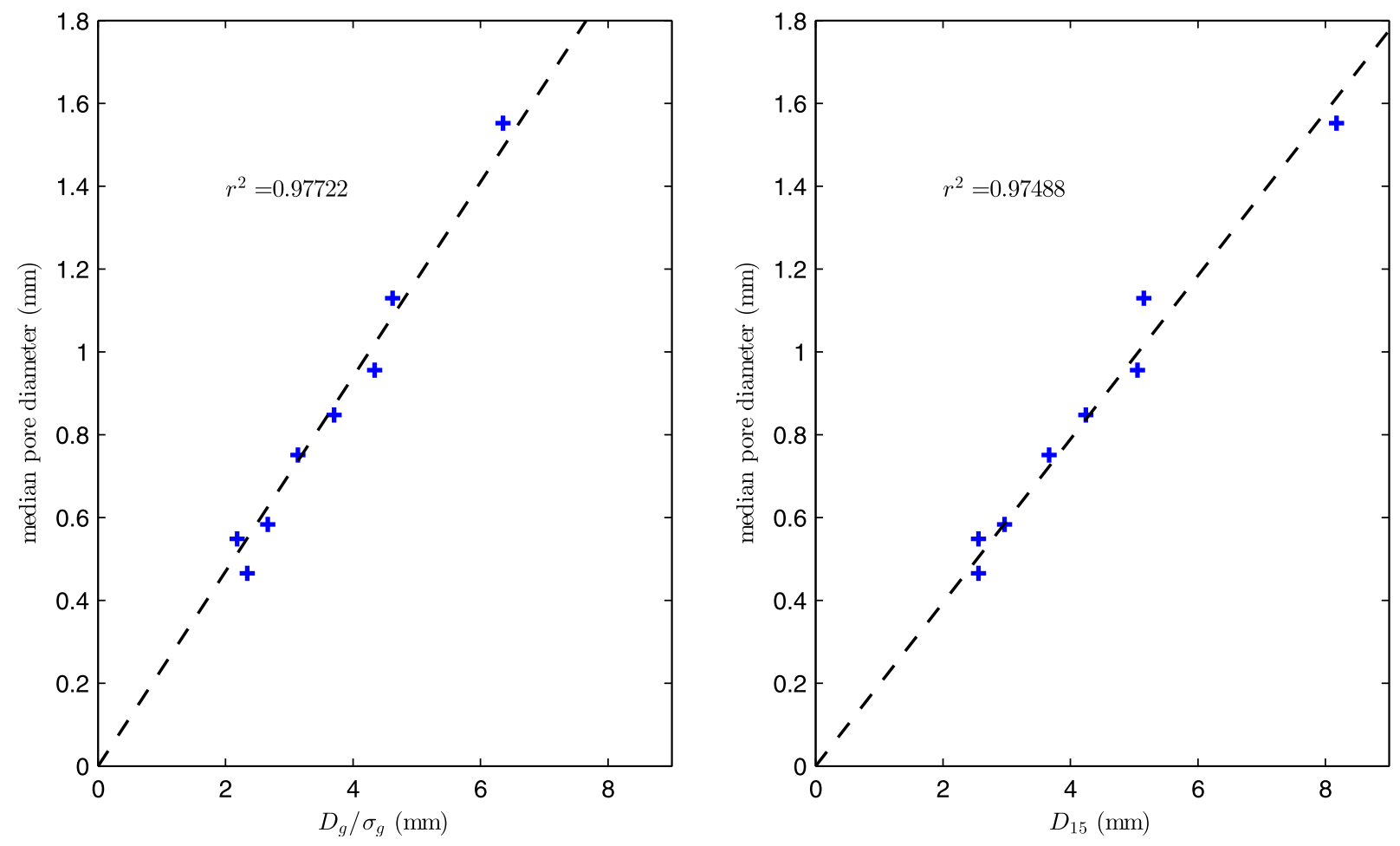

Figure 9. Median pore size of gravels used in Gibson et al. [2010] as a function of the ratio between the geometrical diameter and the standard deviation $D_{g} / \sigma_{g}$ and the $D_{15}$ of the gravels.

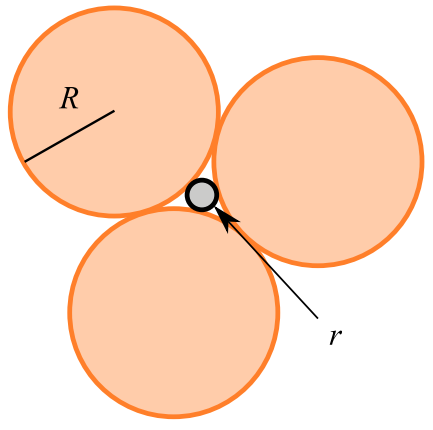

$r=0.16 R$

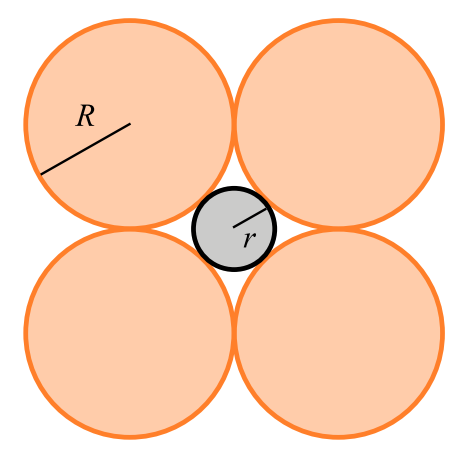

$r=0.41 R$

Figure 10. Theoretical pore throats formed by three and four bed grains. experiments than with free flow experiments is observed in Figure 6. Reproducing this process is out of the scope of this article, although a plausible approach would be to introduce a downward flux of the previously deposited sediment related to turbulent sweeps and their time scale compared to the specified time step. The influence of these turbulent events should be depth dependent [Detert and Parker, 2010].

Previous works highlight the occurrence of a significant expansion of the bed structure in flow conditions just prior to entrainment [Allan and Frostick, 1999; Middleton et al., 2000]. This bed expansion can modify fine sediment distribution within the bed by allowing fine particles to penetrate deeper into the bed. However, the flow conditions used in the experiments of Gibson et al. [2009, 2010] are far from the incipient motion of the gravel bed (15-25\%). Therefore, it does not seem probable that this mechanism could be responsible of the higher fine sediment content observed within the bed in the experimental results compared to the model results.

\subsection{Comparison With a Statistical Analysis}

In this section, the model presented herein is tested against the results obtained based on a statistical analysis performed by Huston and Fox [2015] over a large data set of previous laboratory experiments. This study proposed the following equation to reproduce the FS content depth profile:

$$
F=F_{s} \exp (-k z)
$$

In equation (15), $F_{s}$ is calculated as $F_{s}=\theta_{g}\left(1-\theta_{s}\right), z$ is the vertical coordinate considered positive upward and $k$ is a coefficient defined as 


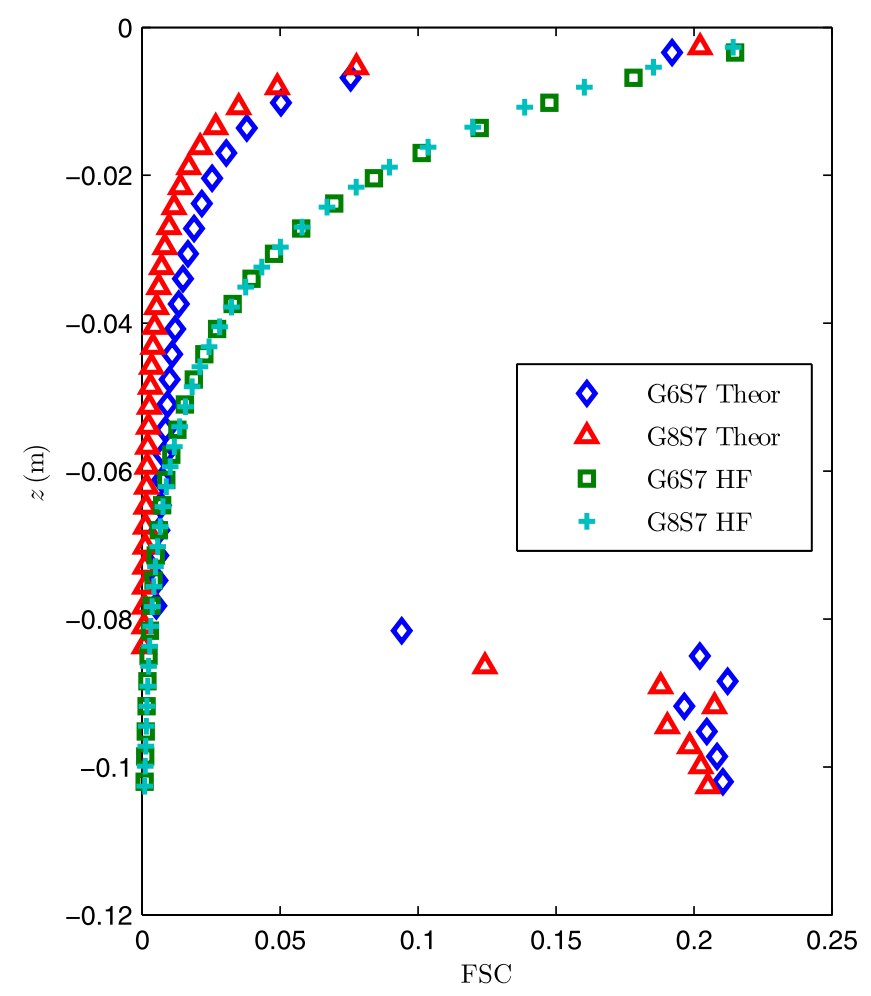

Figure 11. Comparison between the theoretical results calculated with the mathematical model presented herein and the profiles proposed by Huston and Fox [2015] based on their statistical analysis (root-mean-square error normalized with the maximum FSC, G6S7: 0.466; G8S7: 0.429). FSC: fine sediment content.

$$
k=\frac{\ln \left(0.01 / F_{s}\right)}{Z_{C}},
$$

where $Z_{C}$ represents the depth of the clogged layer. Based on the same statistical analysis, Huston and Fox [2015] proposed the following equation to calculate $Z_{C}$ :

$$
Z_{C}^{*}=2.3 \cdot 10^{4} \theta_{g}^{0.6} R^{* 0.1}+2.0 \cdot 10^{4},
$$

where $Z_{C}^{*}$ is the dimensionless clogging depth defined as $Z_{C}^{*}=\left(Z_{C} u_{*}\right) / v$ $\left(u_{*}\right.$ : shear velocity; $v$ : kinematic viscosity) and $R^{*}$ is the roughness Reynolds number defined as $R^{*}=\left(u_{*} k_{s}\right) / v \quad\left(k_{s}\right.$ : roughness length). Figure 11 shows the comparison between the fine sediment content depth profile predicted by the theoretical model and the statistical analysis. The gravel-sand combinations G6-S7 and G8-S7 of Gibson et al. [2010] are considered. Fine sediment content predicted by the theoretical model is lower than that predicted by the statistical analysis (equation (15)). Again, a possible interpretation of this fact is the influence of the surface and subsurface flow on fine sediment distribution within the bed that occurs in the clogging laboratory experiments on which the statistical analysis is based. Furthermore, the exponential coefficient introduced in equation (15) considers that the clogging depth, $Z_{C}$, corresponds to the depth at which fine sediment content is $1 \%$ of the theoretical maximum value. This arbitrary definition has further influence on the obtained results.

\section{Conclusions}

This study develops a mathematical model of fine sediment infiltration into a bed formed by coarser material. The objective is the evaluation of the depth profile of fine sediment content at the equilibrium situation. The model is based on the definition of a trapping coefficient that describes the probability of an infiltrating grain being trapped in a pore throat formed by three bed grains. The bed is subdivided into horizontal layers and the grain size distribution of each layer is updated considering the retained fine sediment, therefore modifying the trapping coefficient. The equilibrium is attained when the fine sediment content at the surface layer reaches a theoretical maximum value based on fine and coarse sediment porosity.

The model is tested against laboratory experiments carried out by Gibson et al. [2009, 2010]. In these studies, fine sediment content depth profile and the mechanism of infiltration (bridging or unimpeded static percolation) were analyzed for different grain size distributions of the bed and the infiltrating sediment. The mathematical model reproduces well the threshold value obtained in the laboratory to distinguish the cases where bridging occurs from those where unimpeded static percolation is observed. Nevertheless, the experimental depth profiles show higher fine sediment content at depth. A possible interpretation of this fact is the influence of pore water velocity in destabilizing the fine grains retained at the pore throats.

The model assumes a simplified geometry that may also be partially responsible for the differences between experimental and simulated results. The analytical approach presented herein is based on a twodimensional simplification of a three-dimensional problem. In natural bed configurations, particles are not necessarily spherical and pores may be formed by more than three particles. Considering these aspects 
from an analytical point of view is difficult and beyond of the scope of this article. Nevertheless, we cannot exclude that pores may be larger in average than the three-particle pores considered in this model. Together with the influence of subsurface flow, these may be the main points explaining the higher fine sediment content observed in the experimental profiles compared to the simulated ones.

\section{Notation}

\section{Symbol}

$D_{g} \quad$ geometric diameter of the gravel.

$d_{g} \quad$ geometric diameter of the sand.

$D_{i} \quad$ diameters used for gravel size discretization.

$D_{i, l} \quad$ diameters used for sediment (gravel and sand) size discretization in layer $I$.

$D_{15} \quad$ diameter for which $15 \mathrm{wt} \%$ of the gravel is finer.

$d_{85}$ diameter for which $85 \mathrm{wt} \%$ of the sand is finer.

$d_{j} \quad$ diameters used for sand size discretization.

$F_{j} \quad$ fine sediment content of diameter $d_{j}$.

$F_{\max }$ maximum value of fine sediment content.

$G_{i} \quad$ cumulated weight fraction corresponding to $D_{i}{ }^{0}$.

$G_{i, l} \quad$ cumulated weight fraction corresponding to $D_{i, l}$ in layer $l$.

$g_{j} \quad$ cumulated weight fraction corresponding to $d_{j}$.

$h_{b} \quad$ bed thickness.

$k_{s} \quad$ bed roughness length.

$N \quad$ number of bed particles per weight unit.

$N_{a} \quad$ number of subdivisions of each interval of the grain size distribution.

$p_{3} \quad$ joint probability distribution of the size of three bed particles.

$p_{b} \quad$ probability density function of gravel size.

$p_{b, i} \quad$ probability density function of gravel size between $D_{i}$ and $D_{i+1}$.

$P_{p} \quad$ cumulative probability distribution of pore throat size.

$p_{p} \quad$ probability density function of pore throat size.

$p_{p, k}$

$q_{j, l} \quad$ flux of sand of diameter $d_{j}$ in layer $l$.

$q_{T o t, 0} \quad$ total flux of sand at the bed surface.

$R^{*} \quad$ roughness Reynolds number.

$u^{*} \quad$ shear velocity.

$x \quad$ pore diameter.

$x_{k} \quad$ values of the pore diameter used for the discretization of the pore size PDF, $p_{p}$.

$z \quad$ depth (zero level at the bed surface).

$Z^{*} \quad$ dimensionless depth (zero level at the bed surface).

$Z_{C} \quad$ depth of the clogged layer.

$Z_{C}^{*} \quad$ dimensionless depth of the clogged layer.

$\alpha \quad$ bias parameter introduced in $p_{3}$.

$\beta_{j} \quad$ trapping coefficient of sand of size $d_{j}$.

$\Delta t \quad$ time step.

$\Delta z \quad$ bed layer thickness.

$\Delta z_{p} \quad$ vertical distance between two pores.

$\gamma \quad$ gravel specific weight.

$\lambda$ parameter defining the accuracy of time discretization.

$v \quad$ water kinematic viscosity.

$\theta \quad$ bed porosity.

$\theta_{g} \quad$ gravel porosity.

$\theta_{s} \quad$ sand porosity.

$\rho_{g} \quad$ gravel density. 
$\sigma_{g} \quad$ variance of gravel size.

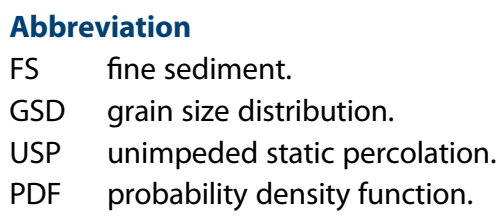

Acknowledgments

The authors express their gratitude to IRSTEA for the funding of this work and Stanford Gibson for allowing to make use of the results from their analyses. The authors will be glad to provide details or the full model code to anyone interested in it (personal communication). Reviewers are also acknowledged for their constructive comments which contributed to improve the quality of the manuscript.

\section{References}

Allan, A. F., and L. Frostick (1999), Framework dilation, winnowing, and matrix particle size: The behavior of some sand-gravel mixtures in a laboratory flume, J. Sediment. Res., 69(1), 21-26.

Blaschke, A. P., K. H. Steiner, R. Schmalfuss, D. Gutknecht, and D. Sengschmitt (2003), Clogging processes in hyporheic interstices of an impounded river, the Danube at Vienna, Austria, Int. Rev. Hydrobiol., 88(3-4), 397-413, doi:10.1002/iroh.200390034.

Blois, G., G. S. Smith, J. L. Best, R. J. Hardy, and J. R. Lead (2012), Quantifying the dynamics of flow within a permeable bed using timeresolved endoscopic particle imaging velocimetry (EPIV), Exp. Fluids, 53(1), 51-76, doi:10.1007/s00348-011-1198-8.

Cho, G. C., J. Dodds, and J. C. Santamarina (2006), Particle shape effects on packing density, stiffness, and strength: Natural and crushed sands, J. Geotech. Geoenviron. Eng., 132(5), 591-602, doi:10.1061/(ASCE)1090-0241(2006)132:5(591).

Cui, Y., and A. C. Wilcox (2005), Numerical modeling of sediment transport upon dam removal: Application to Marmot Dam in Sandy River, Oregon, in Sedimentation Engineering, ASCE Manual 54., pp. 1000-1019, American Society of Civil Engineers (ASCE), Reston, Va.

Cui, Y., J. K. Wooster, P. F. Baker, S. R. Dusterhoff, L. S. Sklar, and W. E. Dietrich (2008), Theory of fine sediment infiltration into immobile gravel bed, J. Hydraul. Eng., 134(10), 1421-1429, doi:10.1061/(ASCE)0733-9429(2008)134:10(1421).

Detert, M., and G. Parker (2010), Estimation of the washout depth of fine sediments from a granular bed, J. Hydraul. Eng., 136(10), 790-793, doi:10.1061/(ASCE)HY.1943-7900.0000263.

East, A. E., et al. (2015), Large-scale dam removal on the Elwha River, Washington, USA: River channel and floodplain geomorphic change, Geomorphology, 228, 765-786.

Einstein, H. (1968), Deposition of suspended particles in a gravel bed, J. Hydraul. Div. Am. Soc. Civ. Eng., 94(5), 1197-1205.

Evans, E., and A. C. Wilcox (2013), Fine sediment infiltration dynamics in a gravel-bed river following a sediment pulse, River Res. Appl., 30(3), 1421-1429, doi:10.1002/rra.2647.

Frings, R. M., M. G. Kleinhans, and S. Vollmer (2008), Discriminating between pore-filling load and bed-structure load: A new porosity-based method, exemplified for the river Rhine, Sedimentology, 55(6), 1571-1593, doi:10.1111/j.1365-3091.2008.00958.x.

Gibson, S., D. Abraham, R. Heath, and D. Schoellhammer (2009), Vertical gradational variability of fines deposited in a gravel framework Sedimentology, 56(3), 661-676, doi:10.1111/j.1365-3091.2008.00991.x.

Gibson, S., D. Abraham, R. Heath, and D. Schoellhammer (2010), Bridging process threshold for sediment infiltrating into a coarse substrate, J. Geotech. Geoenviron. Eng., 136(2), 402-406, doi:10.1061/(ASCE)GT.1943-5606.0000219.

Gibson, S., D. Abraham, R. Heath, and D. Schoellhammer (2011), Visualization and analysis of temporal trends of sand infiltration into a gravel bed, Water Resour. Res., 47, W12601, doi:10.1029/2011WR010486.

Greig, S. M., D. A. Sear, and P. A. Carling (2007), A review of factors influencing the availability of dissolved oxygen to incubating salmonid embryos, Hydrol. Processes, 21(3), 323-334, doi:10.1002/hyp.6188.

Huston, D. L., and J. F. Fox (2015), Clogging of fine sediment within gravel substrates: Dimensional analysis and macroanalysis of experiments in hydraulic flumes, J. Hydraul. Eng., 141, 04015015, doi:10.1061/(ASCE)HY.1943-7900.0001015.

Jones, J. I., A. L. Collins, P. S. Naden, and D. A. Sear (2012), The relationship between fine sediment and macrophytes in rivers, River Res. Appl., 28(7), 1006-1018, doi:10.1002/rra.1486.

Kleinhans, M. G. (2002), Sorting out sand and gravel: Sediment transport and deposition in and-gravel bed rivers, Neth. Geogr. Stud., 293,317 pp. Lauck, T. (1991), A simulation model for the infiltration of sediment into spawning gravel, MS thesis, Humboldt State Univ., Arcata, Calif. Leonardson, R. (2010), Exchange of fine sediments with gravel riverbeds, PhD dissertation, Berkeley Univ., Berkeley, Calif.

Manes, C., D. Pokrajac, V. I. Nikora, L. Ridolfi, and D. Poggi (2011), Turbulent friction in flows over permeable walls, Geophys. Res. Lett., 38, L03402, doi:10.1029/2010GL045695.

Middleton, R., J. Brasington, B. J. Murphy, and L. E. Frostick (2000), Monitoring gravel framework dilation using a new digital particle tracking method, Comput. Geosci., 26(3), 329-340.

Morris, G. L., and J. Fan (1998), Reservoir Sedimentation Handbook, McGraw-Hill, New York.

Peronius, N., and T. J. Sweeting (1985), On the correlation of minimum porosity with particle size distribution, Powder Technol., 42(2), 113121, doi:10.1016/0032-5910(85)80043-7.

Schälchli, U. (1992), The clogging of coarse gravel river beds by fine sediment, Hydrobiologia, 235-236(1), 189-197.

Valdes, J. R., and J. C. Santamarina, (2006), Particle clogging in radial flow: Microscale mechanisms, SPE J., 11(02), $193-198$.

Valdes, J. R., and J. C. Santamarina (2008), Clogging: bridge formation and vibration-based destabilization, Can. Geotech. J., 45(2), 177-184.

Walling, D. E., P. N. Owens, J. Carter, G. J. L. Leeks, S. Lewis, A. A. Meharg, and J. Wright (2003), Storage of sediment-associated nutrients and contaminants in river channel and floodplain systems, Appl. Geochem., 18(2), 195-220, doi:10.1016/S0883-2927(02)00121-X

Wilcock, P. R., and J. C. Crowe (2003), Surface-based transport model for mixed-size sediment, J. Hydraul. Eng., 129(2), 120-128, doi: 10.1061/(ASCE)0733-9429(2003)129:2(120).

Wilcock, P. R., S. T. Kenworthy, and J. C. Crowe (2001), Experimental study of the transport of mixed sand and gravel, Water Resour. Res., 37(12), 3349-3358, doi:10.1029/2001WR000683.

Wood, P. J., and P. D. Armitage (1997), Biological effects of fine sediment in the lotic environment, Environ. Manage., 21(2), 203-217, doi: $10.1007 /$ s002679900019.

Wooster, J. K., S. R. Dusterhoff, Y. Cui, L. S. Sklar, W. E. Dietrich, and M. Malko (2008), Sediment supply and relative size distribution effects on fine sediment infiltration into immobile gravels, Water Resour. Res., 44, W03424, doi:10.1029/2006WR005815.

Zou, R. P., and A. B. Yu (1996), Evaluation of the packing characteristics of mono-sized non-spherical particles, Powder Technol., 88(1), 7179, doi:10.1016/0032-5910(96)03106-3. 